\title{
Creating aversions to locoweed in naive and familiar cattle
}

\author{
M.H. RALPHS, D. GRAHAM, M.L. GALYEAN, AND L.F. JAMES
}

Authors are rangeland scientist, USDA/ARS Poisonous Plant Lab, 1150 E 1400 N, Logan, Ut. 84341; county agent, Clayton, N.M.; professor, West Texas A\&M Univ., Canyon, Tex. 79016.; and research leader, USDA/ARS Poisonous Plant Lab, Logan, Ut.

\begin{abstract}
The objective of this study was to determine if cattle that were familiar with white locoweed (Oxytropis sericea Nutt, ex T\&G) could be aversively conditioned to avoid eating it. In the first preliminary trial, we tried to aversely condition native steers that were already eating locoweed. Six of 12 steers were penned, fed fresh-picked locoweed, then dosed via a stomach tube with lithium chloride $(\mathrm{LiCl}, 200 \mathrm{mg} / \mathrm{kg} \mathrm{BW}$ ). When released into the locoweed-infested pasture, they gradually increased locoweed consumption over the next 5 days. The conditioning procedure was repeated with a lower dose $(100 \mathrm{mg} / \mathrm{kg} \mathrm{BW})$, but locoweed consumption increased within 10 days until they were consuming as much as the non-averted controls. In the second trial, we compared the strength and longevity of aversion between steers that were familiar with locoweed $(n=6)$ and naive steers $(n=6)$. Both groups were averted to locoweed as described in Trial 1 and returned to locoweed-infested pasture. The Familiar group decreased locoweed consumption for the first 2 days, then gradually increased locoweed consumption and extinguished the aversion. The Naive group subsequently refused to graze locoweed. In the third trial, aversions were reinforced following grazing locoweed in the pasture. Three steers from the Familiar group were allowed to graze locoweed for $30 \mathrm{~min}$. periods, then were returned to the pen and dosed with $\mathrm{LiCl}(100 \mathrm{mg} / \mathrm{kg} \mathrm{BW})$. These steers were kept in the pen and allowed to recover for 36 hours. This reinforcement process following grazing was repeated 4 times. Steers in the Reinforced group abstained from eating locoweed when released into the locoweed-infested pasture for the remainder of the trial. Reinforcement of aversions following field grazing of locoweed prevented cattle that were familiar with locoweed from grazing it.
\end{abstract}

Key Words: conditioned taste aversion, cattle grazing, poisonous plant, white locoweed, Oxytropis sericea

Livestock can be trained to avoid eating specific foods through conditioned taste aversion. Zahorik and Houpt $(1977,1990)$ first demonstrated that cattle, sheep, goats, and horses (Houpt and Zahorik 1990) form aversions to feeds paired with an emetic. Provenza (1995) developed principles of both aversive and positive conditioning in sheep. We have developed procedures to aversely condition cattle to avoid eating tall larkspur (Delphinium

The authors thank Stacy Graham for assistance in collecting data

Manuscript accepted 2 Jan. 1996. barbeyi Nutt.) as a management tool to prevent poisoning (Olsen and Ralphs 1986, Lane et al. 1990, Ralphs and Olsen 1990, Ralphs and Cheney 1993).

Ranchers in locoweed areas (Astragalus and Oxytropis spp.) watch their cattle closely and remove those that start eating locoweed. If these cows could be aversively conditioned to avoid eating locoweed, they could be returned to the pastures without risk of further intoxication. However, it is difficult to create aversions to familiar foods.

Novelty of taste is important in creating food aversions because the first exposure presents the orienting response to the new taste (Nachman et al. 1977). If the novel taste is quickly followed with illness, a strong aversion is created to that food. If no harmful effects follow, the food is considered safe. If illness is subsequently paired with a safe food, conflicting messages are sent as to the value of the food. Memory retrieval is confused between a foods acceptance during non-reinforced exposure, and its pairing with illness during conditioning; thus the aversion is weakened. This phenomenon has been referred to as learned safety (Kalat and Rosin 1973), latent inhibition (Lublow 1973), learned familiarity (Best and Barker 1977), and learned non-correlation (Kalat 1977).

However, aversions can be formed to familiar foods, although it is more difficult. Kruz and Levitsky (1982) found that the aversion was strongest when a novel food was presented in a familiar environment, but a moderate aversion was created to a familiar food in a familiar environment. More pairings of the familiar taste with illness are required and the aversions extinguish faster (Fenwick et al. 1975).

The objective of this study was to determine if cattle that were familiar with white locoweed (Oxytropis sericea Nutt ex T\&G) could be aversively conditioned to avoid eating it. Specific objectives were: 1) to verify the difficulty in creating an aversion to locoweed as a familiar food; 2) compare the strength and longevity of an aversion to locoweed in steers that were familiar with it compared to naive steers; and 3) determine if reinforcement under field grazing conditions can successfully maintain an aversion in steers that were familiar with locoweed.

\section{Methods}

The experiments were conducted in field grazing trials in Union County, N.M., $16 \mathrm{~km}$ south of Des Moines. The site was an old field thet had reverted to short-grass prairie. Dominant 
species included bluegrama (Bouteloua gracilis (H.B.K.) Lag. ex Steudel), western wheatgrass (Elymus smithii (Rybd) Gould), squirreltail (Elymus elymoides (Raf.) Swezey), and white locoweed. Standing crop was clipped at the beginning of each trial to determine forage availability. Ten $.25 \times 1 \mathrm{~m}$ quadrats were systematically located at 20 -step intervals along paced transects running through the middle of the pastures. Forage classes (warm-season grasses, cool-season grasses, broom snakeweed, locoweed, and other forbs) were clipped at ground level, dried at $60^{\circ} \mathrm{C}$ for 48 hours, and weighed.

\section{Trial 1, Establishing Aversions in Steers Familiar with Locoweed}

This was a preliminary trial in which we tried to aversively condition steers that were already eating locoweed. Twelve native steers $(230 \mathrm{~kg}$ ) had been grazing locoweed on the site for 20 days in a previous trial to determine the influence of over-wintering regimen on locoweed consumption (Ralphs et al. 1997). Locoweed averaged $30 \%$ of their diets; however, maximum locoweed consumption reached $75 \%$ of diets on some days. Steers were allocated to 2 treatment groups (Averted or Control) so that the same number of steers from the previous treatment groups were represented in each new group.

Steers in the Averted group (n-6) were penned and feed was withheld overnight. Fresh-picked locoweed was offered the next morning, and we observed that all steers readily consumed it. Steers were then restrained in a chute and dosed with lithium chloride ( $\mathrm{LiCl}, 200 \mathrm{mg} / \mathrm{kg} \mathrm{BW}$ ) using a stomach tube. The regular morning feed was withheld so there was no interference between the induced illness and the taste of other feed. Sudangrass hay was fed in the evening, and for the next 3 days while the steers recovered. Fresh locoweed was offered in the morning and evening of the third and fourth day to test the aversion, but all steers refused it. They were then released into the locoweed-infested pasture. Two pastures $(6.8 \mathrm{ha})$ were fenced with temporary electric fence and treatment groups were randomly allotted to separate pastures.

Diet composition was estimated by a bite count technique. Each steer was observed for 5-min. periods during the major grazing periods during the day (3-6 observations per day). The number of bites of each forage class was recorded (cool-season grass, warm-season grass, locoweed, and other forbs), and the percentage of each class was calculated on a daily basis. Percentage of bites of each forage class was analyzed by analysis of variance (ANOVA) in a split-plot design comparing groups over days of the trial. Differences between groups were tested by the animal (within group) factor, and the day and treatment $x$ day interaction was tested by the residual error. Individual animals were the experimental units to which the aversion treatment was applied, and the individual response of each animal was measured in the pastures. The pastures were merely the area in which the response to aversions were expressed. The treatment groups were grazed in separate pastures to prevent the non-averted group from influencing the averted group to graze locoweed. We switched the groups between the pastures half way through the trial to minimize any pasture difference. Furthermore, we analyzed for differences in locoweed consumption between the pastures by ANOVA, using animals (within pastures) to test for differences between pastures.

\section{Trial 2, Familiar vs Naive Steers}

Twelve steers were obtained from the New Mexico State Univ. Clayton Livestock Research Center (large framed, mixed Continental and British crosses, $210 \mathrm{~kg}$ ). These steers were new to the area and had never been exposed to locoweed. The steers were allotted randomly to 2 treatment groups (Familiar or Naive). The Familiar group was placed on locoweed-infested rangeland (6 ha) on 23 April, and allowed to graze locoweed for 16 days. Locoweed averaged $56 \%$ of the total bites. The Naive group grazed on locoweed-free range during this period at the Clayton Research Center (25 ha). Both groups were then averted to locoweed.

During aversion conditioning, both groups were penned at the study site, fasted overnight, and offered fresh-picked locoweed $(15 \mathrm{~kg}$ ) the ncxt morning. The groups were mixed together so social facilitation helped induce the naive steers to eat locoweed. We observed all steers eating the locoweed. Steers were then restrained in a chute, dosed with $\mathrm{LiCl}(200 \mathrm{mg} / \mathrm{kg} \mathrm{BW})$, and allowed to recover for 3 days. They were fed sudangrass hay while in the pen. On the morning of the third day, the steers were offered locoweed to test the aversion. Four steers in the familiar group ate locoweed and were dosed with a lower dose of $\mathrm{LiCl}$ $(100 \mathrm{mg} / \mathrm{kg} \mathrm{BW})$. The steers were offered locoweed the next day, which they refused, then were released into the locoweed-infested pasture.

Diets were quantified by bite count as described in Trial 1. The Naive and Familiar groups grazed in 2 adjacent pastures ( 3 ha each) for 6 days. Percentage of bites of each forage class was analyzed by ANOVA in a split-plot design comparing groups over the 6-day trial, as described in Trial 1. Individual steers were considered experimental units. However, the preconditioning treatments (Familiar or Naive to locoweed) were applied to the groups. The aversion treatment was applied to individual steers, and their individual response to the aversion was measured in the pastures as described above. The groups were switched to the other pasture half way through the trial to reduce potential differences in diet selection between pastures. Differences in diets between pastures were compared using a similar model.

\section{Trial 3, Reinforcement of Aversion in the Pasture}

The Familiar group gradually lost their aversion to locoweed in Trial 2. Steers in the Familiar group were systematically allocated into 2 subgroups. Three steers eating the most locoweed in Trial 2 were placed in the Reinforced group, whereas the 3 steers eating the least amount of locoweed remained in the Familiar group. The Familiar group returned to the pasture and served as a control to the Reinforced group. Steers in the Reinforced group were fasted overnight, then offered fresh locoweed, which they refused. They were then released into a small pasture $(.5 \mathrm{ha})$ heavily infested with locoweed, and allowed to graze for $30 \mathrm{~min}$. during which bite counts were recorded. All steers grazed large amounts of locoweed and were brought back to the pen and dosed with $\mathrm{LiCl}(100 \mathrm{mg} / \mathrm{kg} \mathrm{BW})$. They were allowed to recover for $36-$ hours, and the process was repeated for 4 cycles.

The Reinforced group was released into a larger 3 ha pasture and allowed to graze for the 8 day trial. Half way through the trial, steers from the Familiar and Reinforced groups were switched between pastures to reduce potential pasture differences. Five-minute bite counts were recorded and percentage of forage classes in diets were compared between groups by ANOVA in a split-plot design over days of the trial as described 
in Trial 1. Differences in diets between pastures were also compared using a similar model.

\section{Results}

There was no difference in standing crop of forage classes between the pastures at the beginning of the trials (Table 1). Furthermore, there were no differences in locoweed consumption between pastures in any of the trials $(P>0.05)$.

Table 1. Standing crop of forage classes at the beginning of the trials.

\begin{tabular}{|c|c|c|c|c|c|c|}
\hline Year $T_{Y}$ & $\begin{array}{l}\text { Warm- } \\
\text { season } \\
\text { grass }\end{array}$ & $\begin{array}{l}\text { Cool- } \\
\text { season } \\
\text { grass }\end{array}$ & $\begin{array}{l}\text { Other } \\
\text { forbs }\end{array}$ & $\begin{array}{l}\text { Broom } \\
\text { snake- } \\
\text { weed }\end{array}$ & $\begin{array}{l}\text { Loco- } \\
\text { weed }\end{array}$ & Total \\
\hline & \multicolumn{6}{|c|}{$+\ldots \ldots(\mathrm{kg} / \mathrm{ha} \pm \mathrm{SE})+\ldots \ldots$} \\
\hline 19941 & $124 \pm 10$ & $14 \pm 3$ & $54 \pm 13$ & $67 \pm 16$ & $28 \pm 5$ & $287 \pm 26$ \\
\hline 19952 & $534 \pm 62$ & $83 \pm 17$ & $99 \pm 23$ & - & $130 \pm 34$ & $846 \pm 64$ \\
\hline 19953 & $383 \pm 32$ & $21 \pm 12$ & $40 \pm 17$ & - & $91 \pm 21$ & $595 \pm 44$ \\
\hline
\end{tabular}

\section{Trial 1, 1994}

A visual comparison of locoweed consumption before aversion conditioning indicates there was little difference between treatment groups (Fig. 1). Following conditioning, the Averted group consumed less locoweed than the Control group $(P=0.001$, Table $2)$, but there was a treatment $X$ day interaction $(P=0.0001)$. The averted group gradually increased locoweed consumption up to $10 \%$ of their bites (Fig. 1). They were brought back into the pens on 1 May, fasted overnight, then offered fresh picked locoweed,

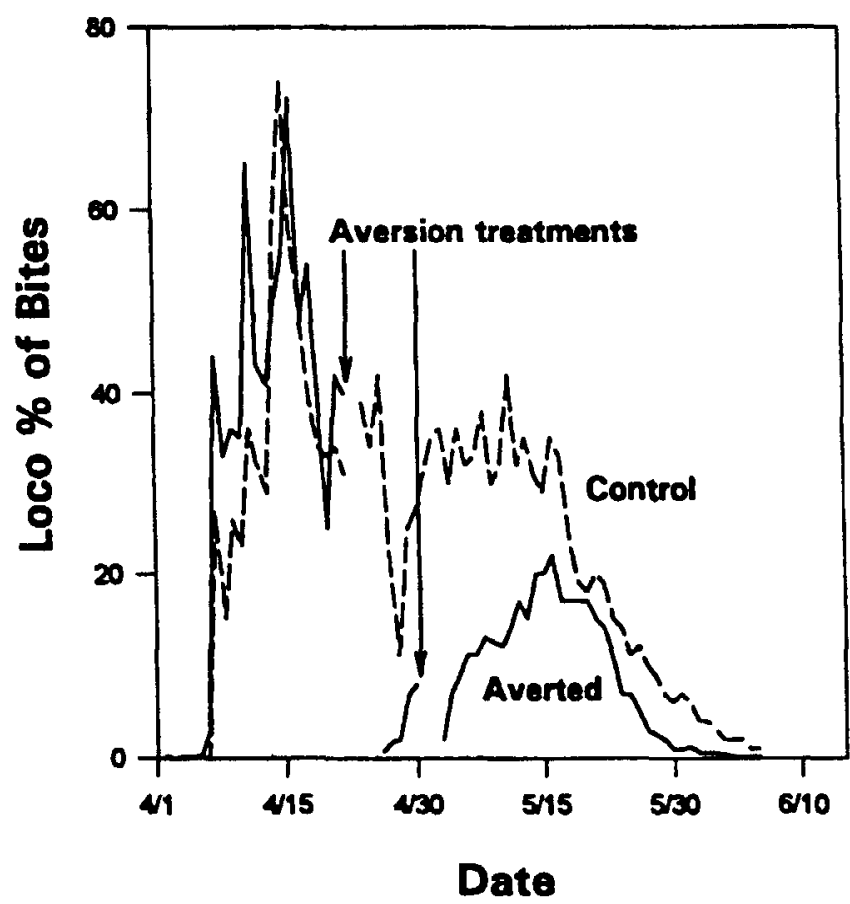

Fig. 1. Trial 1-Locoweed consumption of Control and Averted steers in 1994.
Table 2. Percentage of bites ( \pm standard error) of forage classes in steer diets in Trial 1, 1994.

\begin{tabular}{lcccc}
\hline \hline Group & $\begin{array}{c}\text { Cool-season } \\
\text { grass }\end{array}$ & $\begin{array}{c}\text { Warm-season } \\
\text { grass }\end{array}$ & $\begin{array}{l}\text { Other } \\
\text { forbs }\end{array}$ & Locoweed \\
\hline & $\ldots \ldots \ldots$ & $\ldots \ldots \ldots$ & $\ldots$ & $\ldots$ \\
Averted & $16^{\mathrm{a}} \pm .69$ & $62^{\mathrm{a}} \pm .60$ & $13^{\mathrm{a}} \pm .57$ & $8^{\mathrm{a}} \pm .51$ \\
Control & $14^{\mathrm{a}} \pm .38$ & $53^{\mathrm{b}} \pm .70$ & $12^{\mathrm{a}} \pm .56$ & $21^{\mathrm{b}} \pm .90$ \\
\hline
\end{tabular}

Means in the same column followed by the same letter are not significantly differen $(P<0.05)$.

which they refused. They were fasted another day and offered locoweed again on 3 May. Two steers ate locoweed and were dosed a second time with a reduced level of $\mathrm{LiCl}(100 \mathrm{mg} / \mathrm{kg}$ $\mathrm{BW}$ ). There was little locoweed consumption in the pasture for 2 days, then consumption began to increase. By 7 May, all averted animals were eating locoweed, and eventually consumed as much locoweed as the Control group (Fig. 1).

Locoweed consumption started to decrease on 19 May and essentially ceased by 2 June (Fig. 1). Nighttime temperatures increased and warm-season grasses began rapid growth. In previous studies, locoweed consumption ceased when warm-season grasses became abundant (Ralphs et al. 1993, 1994, 1997).

\section{Trial 2, Familiar vs Naive Steers}

Steers in the Familiar group consumed locoweed for an average of $56 \%$ of bites before aversion conditioning (Fig. 2). Following conditioning, the Familiar group consumed about the same amount of locoweed as before conditioning on the first round of bite counts, but greatly decreased locoweed consumption on the second round of counts about an hour later (Fig. 2). Little locoweed was consumed the second day. Steers increased

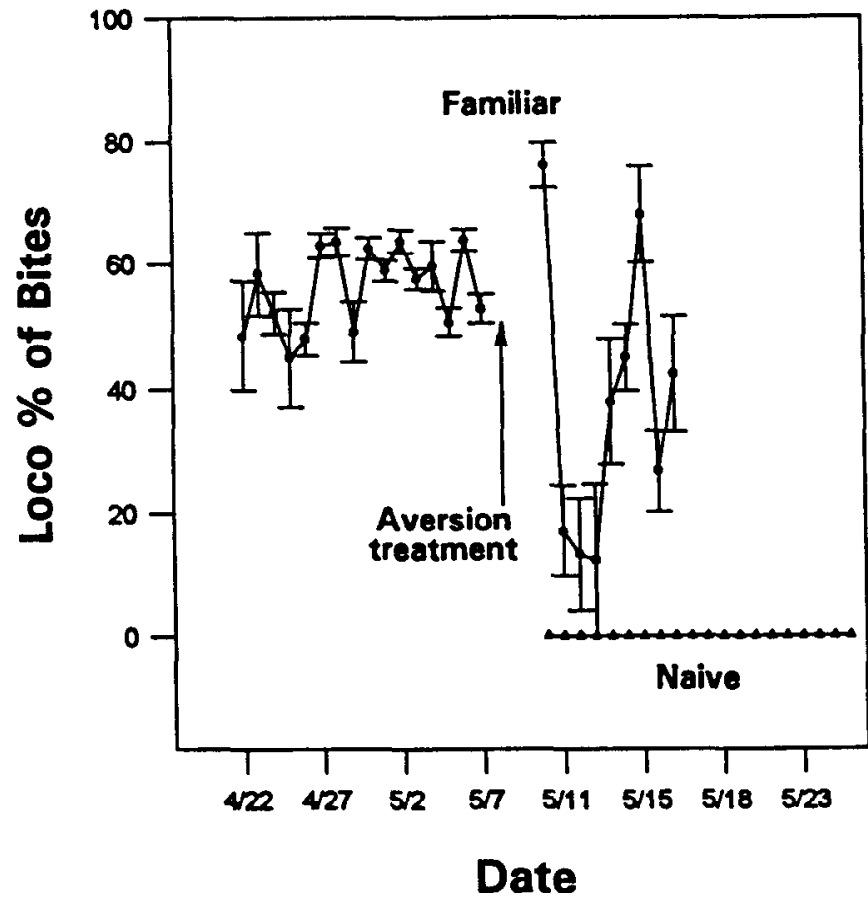

Fig. 2. Trial 2-Locoweed consumption ( $\%$ of bites \pm SE) of steers familiar with locoweed, and of the Familiar and Naive group following aversion conditioning. 
Table 3. Percentage of bites ( \pm standard error) of forage classes in diets of Familiar and Naive groups in Trial 2, 1995.

\begin{tabular}{lcccc}
\hline \hline Group & $\begin{array}{c}\text { Cool-season } \\
\text { grass }\end{array}$ & $\begin{array}{c}\text { Warm-season } \\
\text { grass }\end{array}$ & $\begin{array}{l}\text { Other } \\
\text { forbs }\end{array}$ & Locoweed \\
\hline & $\ldots \ldots \ldots \ldots$ & $\ldots \ldots$ & $\ldots$ \\
Familiar & $35^{\mathrm{a}} \pm 3.1$ & $20^{\mathrm{a}} \pm 2.4$ & $8^{\mathrm{a}} \pm 1.5$ & $37^{\mathrm{a}} \pm 3.6$ \\
Naive & $23^{\mathrm{a}} \pm 3.2$ & $68 \pm 3.2$ & $9^{\mathrm{a}} \pm 1.3$ & $0^{\mathrm{b}} \pm 0$ \\
\hline
\end{tabular}

${ }^{26}$ Means in the same column followed by the same letter are not significantly different $(P<0.05)$.

locoweed consumption up to an average of $37 \%$ of bites for the remainder of the trial (Table 3 ).

The Naive group did not consume any locoweed in the pasture (Fig. 2). However, they consumed more warm-season grasses than the Familiar group (Table 3). The locoweed-free pasture they grazed before aversion conditioning had mostly dormant warmseason grasses which they were apparently conditioned to eating.

\section{Trial 3, Reinforcement of Aversion in the Pasture}

The Reinforced group refused to eat fresh-picked locoweed when offered in the pen, but readily consumed locoweed in the small 0.5 ha pasture ( $86 \%$ of bites). Locoweed consumption decreased following each successive dose of $\mathrm{LiCl}$ paired with pasture grazing of locoweed (Fig. 3). When released into the larger locoweed-infested pasture, the Reinforced group abstained from eating locoweed for the remainder of the trial. The Familiar group continued eating locoweed for an average of $21 \%$ of bites (Table 4). Steers selected for the Familiar group had the lowest mean consumption of locoweed in Trial 2; thus they probably underestimated locoweed consumption of a non-averted control group.

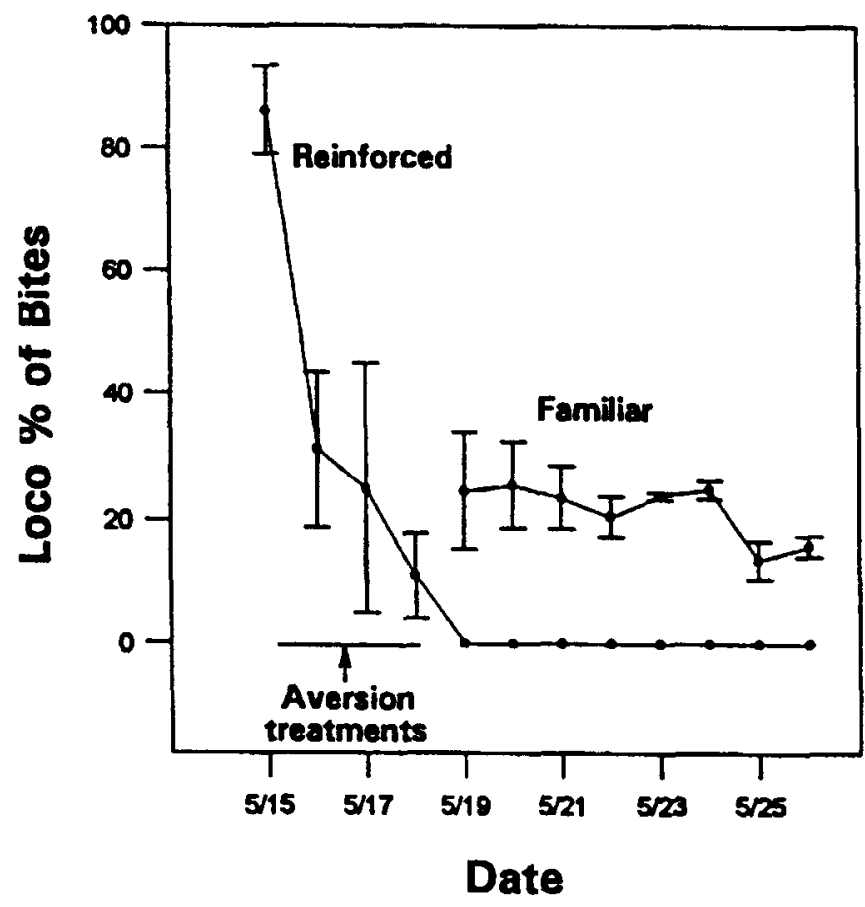

Fig. 3. Trial 3 - Locoweed consumption ( $\%$ of bites \pm SE) of Familiar and Reinforced steers following reinforcement of aversion in the pasture.
Table 4. Percentage of bites ( \pm standard error) of forage classes in diets of Familiar and Reinforced groups in Trial 3, 1995.

\begin{tabular}{lcccc}
\hline Group & $\begin{array}{c}\text { Cool-season } \\
\text { grass }\end{array}$ & $\begin{array}{c}\text { Warm-season } \\
\text { grass }\end{array}$ & $\begin{array}{c}\text { Other } \\
\text { forbs }\end{array}$ & Locoweed \\
\hline & $\ldots \ldots \ldots$ & $\ldots \ldots \ldots \ldots$ & $\ldots \ldots \ldots$ \\
Familiar & $25^{\mathrm{a}} \pm 1.4$ & $39^{\mathrm{a}} \pm 1.7$ & $15^{\mathrm{a}} \pm 1.2$ & $21^{\mathrm{a}} \pm 1.5$ \\
Reinforced & $29^{\mathrm{a}} \pm 2.3$ & $48^{\mathrm{b}} \pm 2.0$ & $24^{\mathrm{b}} \pm 1.9$ & $0^{\mathrm{b}} \pm 0$ \\
\hline
\end{tabular}

Means in the same column followed by the same letter are not significantly different $(\mathrm{P}<\mathbf{0 . 0 5})$.

\section{Discussion}

Trial 1 illustrates the difficulty in creating aversions to familiar plants. Steers consumed locoweed for an average of $30 \%$ of their diets before aversion conditioning. They were dosed with a relatively high dose of $\mathrm{LiCl}$ and they refused to consume any locoweed when subsequently offered it in the pen. When released into the pasture, they gradually started eating locoweed, and after 6 days, were returned to the pen for a reinforcement dose. After an overnight fast, all steers refused locoweed in the pen. After a second day of fasting, only 2 of 6 steers consumed locoweed. The majority of steers could not be starved to eat locoweed in the pen, even though they readily consumed it in the pasture. Context clues associated with the environment where the aversions are formed play a role in retrieval of the taste-illness association (Bonardi et al. 1990, Archer et al. 1985). Steers avoided locoweed in the pen where it was paired with illness, but accepted it in the pasture because there was no negative reinforcement from grazing it. We had similar experiences in aversively conditioning cattle to avoid eating tall larkspur. We created the aversion in a pen by offering yearling heifers fresh larkspur, then dosed them with $\mathrm{LiCl}$. They were transported to tall larkspurinfested mountain rangeland where the aversion extinguished while the heifers grazed with non-averted cohorts. However, the aversion renewed when the heifers were brought back to the pen and the environment where the aversion was created (Ralphs and Olsen 1990). These 2 studies emphasize the difficulty of reinforcing an aversion in the pen; animals must consume the plant prior to dosing with the emetic.

Results from trial 2 supports the conclusion from trial 1: aversions are difficult to create to familiar foods. Naive steers required only one dose of $\mathrm{LiCl}$ to be completely averted to locoweed for the remainder of the trial. Four of 6 steers in the Familiar group were dosed twice and still the aversion rapidly extinguished. Burritt and Provenza (1995) reported that sheep preexposed to wheat or rice for 7 days or longer, rapidly extinguished aversions to the respective grains, compared to sheep that were averted to these grains when they were novel. This verifies the fact that novelty of a food is important in creating a strong and persistent aversion (Nachman et al. 1977).

An unusual phenomenon occurred in Trial 2 when the Familiar group were released from the pen into the pasture following aversion conditioning. On the first round of bite counts, they selectively grazed locoweed at about the same level as before conditioning. However on the second round of bite counts about an hour later, all but 1 steer greatly decreased intake of locoweed. The next day, all but the 1 steer abstained from eating locoweed. On the third day, all steers started eating locoweed again. 
Theoretically, the feeding response is a complex integration of the physiological state of the animal (degree of hunger), the flavor of the food, its nutrient value or potential toxic effect, the context in which the food is consumed, and the social interaction between grazing animals (C.D. Cheney, personal communication). When the steers were released from the pen, they resumed eating locoweed in the pasture as they had prior to aversion conditioning. Their prior acceptance of locoweed as a preferred food, and the social facilitation of all steers in the group eating it, apparently overwhelmed the more recent association of the tasteillness pairing. However, within an hour, 5 of 6 steers made the association between the taste of locoweed in the pasture and the prior LiCl-induced illness and stopped eating locoweed. An hedonic shift occurred in the palatability and subsequent acceptance of locoweed. Garcia et al. (1977) suggested that "following aversion conditioning, the food may look, and even smell attractive, but the animal may be surprised that it tastes bad." The longer period of time it took our steers to make the association between locoweed in the pasture and the previously induced illness, may have been due to locoweed's familiarity and previous preference when grazed in the pasture. Adverse feedback from the locoweed toxin swainsonine would not be expected in this short period. Locoism is a chronic poisoning, requiring several weeks of locoweed consumption. Furthermore, the mechanism of action is at the cellular level and would not cause gastrointestinal malaise, which is required to be associated with taste to form an aversion. Over the next few days, all steers gradually increased consumption of locoweed and the aversion eventually extinguished. Post conditioning exposure to a food without reinforcement from the illness can extinguish an aversion (Kraemer and Spear 1992). A second hedonic shift occurred when illness did not follow consumption of locoweed in the pasture. The positive feedback from nutrients in locoweed, in the absence of the induced illness, apparently elevated its palatability (Provenza 1995).

In Trial 3, the subgroup of Familiar steers eating the most locoweed in Trial 2 were selected for the reinforcement treatment. They refused to eat fresh-picked locoweed in the pen, but readily grazed locoweed in the pasture. The conditioning protocol was changed to dose these steers after grazing locoweed in the pasture. These steers were slow to form an aversion to locoweed that they grazed in the pasture; one steer required 4 doses of $\mathrm{LiCl}$, another required 3 doses, and the third required 2 . However, this method successfully averted these steers that were familiar with locoweed. They abstained from eating locoweed for the remainder of the trial.

\section{Conclusions}

It is difficult to create an aversion to a plant to which cattle are familiar. They learned that eating locoweed in the pen was associated with illness, but sampling it in the field without adverse consequences gradually extinguished the aversion.

The protracted method of reinforcing the aversion following short grazing periods in the pasture was successful. This was an extremely difficult test for the Reinforced steers. They had gone through an aversion and extinction period in Trial 2 , and had the greatest preference for locoweed of all the steers in the study. This method of repeatedly allowing cattle to graze a particular plant, then dosing them with an emetic was successful in creating a complete aversion to a familiar plant.

The other significant finding of this study was the relative ease of creating an aversion to an unfamiliar plant in the Naive group. In other studies, naive cattle have been conditioned to avoid eating larkspur, and the aversion lasted over 2 (Lane et al. 1990) or 3 years (Ralphs 1997) without any reinforcement while the averted cattle grazed separately. It appears that aversions are retained in long-term memory.

Conditioned food aversion may be a relatively simple procedure to train naive animals to avoid grazing particular poisonous plants. Animals that are familiar with the plant will require reinforcement with repeated doses of an emetic following field grazing sessions. Ranchers in locoweed areas watch their cattle and remove those that start eating locoweed. Creating and reinforcing aversions to locoweed in these cattle may prevent progression of intoxication, and prevent them from influencing others to graze locoweed.

\section{Literature Cited}

Archer, T., P.O. Sjoden, and L.G. Nilsson. 1985. Contextual control of taste-aversion conditioning and extinction, p.225-271. In: P.D. Balsam and A. Tomie (eds), Context and Learning. Lawrence Erlbaum Assoc., Hillsdale N.J.

Best, M.F. and L.M. Barker. 1977. The nature of learned safety and its role in the delay of reinforcement gradient, p. 295-325. In: L.M. Barker, M.R. Best, and M. Domjan (eds), Learning Mechanisms in Food Selection. Baylor Univ. Press, Waco, Tex.

Bonardi, C., R.C. Honey, and G. Hall. 1990. Context specificity in flavor-aversion learning: extinction and blocking trials. Anim. Lear. Behav. 18:229-237.

Burritt, E.A. and F.D. Provenza. 1996. Amount of experience and prior illness affect the acquisition and persistence of conditioned food aversions in lambs. Appl. Anim. Behavor. Sci. 48:73-80.

Fenwick, S., P.J. Miluka, and S.B. Klein. 1975. The effect of different levels of pre-exposure to sucrose on the acquisition and extinction of a conditioned aversion. Behav. Biol. 14:231-235.

Garcia, J., W.G Hankins, and J.D. Coil. 1977. Koalas, men and other conditioned gastronomes, p. 195-218. In: N.W. Milgram, L. Krames, and T.M. Alloway (eds), Food Aversion Learning. Plenum Press, New York.

Houpt, K.A. and D.M Zahorik. 1990. Taste aversion learning in horses. J. Anim. Sci. 68:2340-2344.

Kalat, J.W. 1977. Status of "learned safety" or "learned noncorrelation" as mechanisms in taste-aversion learning, p. 273-294. In: L.M. Barker, M.R. Best, and M. Domjan (eds), Learning Mechanisms in Food Selection. Baylor Univ. Press, Waco, Tex.

Kalat, J.W. and P. Rozin. 1973. "Learned safety" as a mechanism in long-delay taste-aversion learning in rats. J. Compar. Physiol. Psychol. 83:198-207.

Kraemer P.J. and N.E. Spear. 1992. The effect of nonreinforced stimulus exposure on the strength of a conditioned taste aversion as a function of retention interval: Do latent inhibition and extinction involve a shared process? Anim. Learn. Behav. 20:1-7.

Kruz, E.M. and D.A. Levitsky. 1982. Novelty of contextual cues in taste aversion learning. Anim. Learn. Behav. 10:229-232.

Lane, M.A., M.H. Ralphs, J.D. Olsen, F.D. Provenza, and J.A. Pfister. 1990. Conditioned taste aversion: potential for reducing cattle loss to larkspur. J. Range Manage. 43:127-131.

Lublow, R.E. 1973. Latent inhibition. Psychol. Bull. 79:398-407.

Nachman, M., J. Rauschenberger, and J.H. Ashe. 1977. Stimulus characteristics in food aversion learning, p. 105-131. In: N.W. Milgram, L. Krames, and T.M. Alloway (eds), Food Aversion Learning. Plenum Press, N.Y.

Olsen J.D. and M.H. Ralphs. 1986. Feed aversion induced by intraruminal infusion with larkspur extract in cattle. Amer. J. Vet. Res. 47:1829-1833. 
Provenza, F.D. 1995. Postingestive feedback as an elementary determinant of food preference. J. Range Manage. 48:2-17.

Ralphs, M.H. 1997. Long term retention of aversions to tall larkspur in naive and native cattle. J. Range Manage. 50:367-370.

Ralphs, M.H. and C.D. Cheney. 1993. Influence of cattle age, lithium chloride dose level, and food type in the retention of food aversions. J. Anim. Sci. ? 1:373-379.

Ralphs, M.H. and J.D. Olsen. 1990. Overcoming the influence of social facilitation in training catlle to avoid eating larkspur. J. Anim. Sci. 68:1944-1952.

Ralphs, M.H., D. Graham, and L.F. James. 1994. Cattle grazing white locoweed in New Mexico: Influence of grazing pressure and phenological growth stage. J. Range Manage. 47:270-274.
Ralphs, M.H., D. Graham, R.J. Molyneux, and L.F. James. 1993. Seasonal grazing of locoweeds by cattle in northeastern New Mexico. J. Range Manage. 46:416 420.

Ralphs, M.H., D. Graham, M.L. Galyean, and L.F. James. 1997. Influence of over-wintering feed regimen on consumption of locoweed by steers. J. Range Manage. 50:247-249.

Zahorik, D.M. and K.A. Houpt. 1977. The concept of nutritional wisdom: applicability of laboratory learning models to large herbivores. p. 45-67. In:L.M. Barker, M.R. Best, and M. Domjan (eds), Learning Mechanisms in Food Selection. Baylor Univ. Press, Waco, Tex.

Zahorik, D.M. and K.A. Houpt. 1990. Taste-aversion learning in three species of ruminants. Appl. Anim. Behav. Sci. 26:27-39.

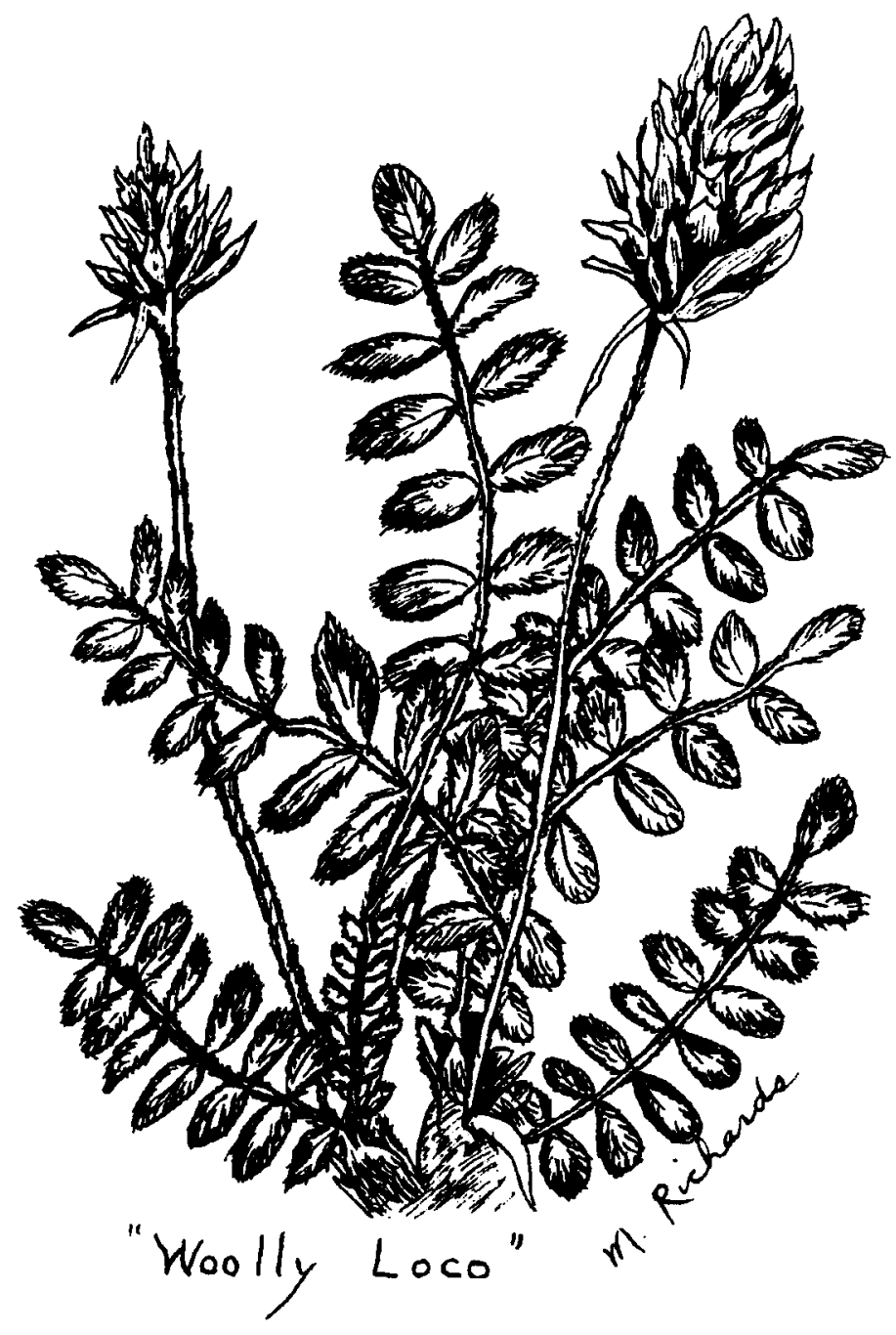

